\title{
ОПТИМИЗАЦИЯ НУТРИТИВНОЙ ПОДДЕРЖКИ ПАЦИЕНТОВ С РЕЗЕКЦИЕЙ ТОНКОЙ КИШКИ В ЭКСТРЕННОЙ ХИРУРГИИ
}

\section{OPTIMIZATION OF NUTRITIONAL SUPPORT FOR PATIENTS WITH SMALL BOWEL RESECTION IN EMERGENCY SURGERY}

\section{A. Varganova \\ E. Krasnov \\ V. Darwin \\ A. Askerova \\ S. Mamedov}

Objective: to improve the results of treatment of patients with emergency surgical pathology of the small intestine by optimizing the nutritional support program.

Material and methods: increasing the efficiency of treatment of patients with emergency surgical pathology of the small intestine by developing a nutritional support program.

Results: the developed step-by-step program of early enteral nutrition in patients with small bowel resection contributes to the rapid restoration of protein-energy needs, which has a positive effect on the restoration of gastrointestinal tract function, a decrease in the incidence of anastomotic healing disorders, a reduction in the duration of inpatient treatment and a decrease in postoperative mortality.

Keywords: early enteral nutrition, small intestine resection, efficiency.

\section{Введение}

$\mathbf{H}$ аиболее частым поводом для резекции тонкой кишки в экстренной хирургии является ее некроз (гангрена), возникающий вследствие острого нарушения мезентериального кровообращения, а именно тромбоза или тромбэмболии в бассейне
Варганова Александра Николаевна Аспирант, Сургутский Государственный Университет

Alexvarg24@yandex.ru

Краснов Евгений Анатольевич

Доцент, Сургутский государственный университет

Дарвин Владимир Васильевич Профессор, Сургутский государственный университет

Аскерова Анастасия Александровна Аспирант, Сургутский государственный университет

Мамедов Султан Гаджи- Оглы Аспирант, Сургутский государственный университет

Аннотация. Цель исследования: повышение эффективности лечения больных с экстренной хирургической патологией тонкой кишки путем разработки программы нутритивной поддержки.

Материал и методы. Проведен анализ схем нутритивной поддержки 60 пациентов оперированных на тонкой кишке (30 пациентов в группе энтерального питания, 30 пациентов - парентеральное питание). В ходе исследования была изучена динамика лабораторных параметров, время восстановления функции ЖКТ, частота послеоперационных осложнений, послеоперационная летальность, длительность стационарного лечения в исследуемых группах.

Результаты. Разработанная поэтапная программа раннего энтерального питания у пациентов с резекцией тонкой кишки способствует быстрому восстановлению белково-энергетических потребностей, что позитивно влияет на восстановление функции желудочно-кишечного тракта, снижению частоты нарушений заживления анастом0зов, сокращению длительности стационарного лечения и уменьшению послеоперационной летальности.

Ключевые слова: раннее энтеральное питание, резекция тонкой кишки, эффективность.

верхних брыжеечных сосудов (артерии и вены), а также вследствие странгуляционной кишечной непроходимости и ущемленых грыжах. В настоящее время одной из сложных и нерешенных проблем в экстренной абдоминальной хирургии остается острое нарушение мезентериального кровообращения, встречающееся в практике хирурга у 0,1-0,2\% всех больных, госпитали- 
зированных в хирургические отделения $[1,10]$. Сложная клиническая картина, трудности ранней диагностики данной патологии, тяжелые фоновые заболевания сердечно-сосудистой системы обусловливают позднюю госпитализацию больных и запоздалое хирургическое вмешательство, нередко уже в условиях некротических изменений кишечника $u$ распространенного перитонита. Патологические изменения в кишечнике, так и брюшной полости при острой кишечной непроходимости зависят от ее вида. При странгуляционной непроходимости первично нарушается кровообращение отдельного участка кишки, поэтому ишемические и некробиотические ее изменения наступают значительно раньше и более выражены.

Несмотря на применение современных лабораторных и рентгенологических исследований, лечебных мероприятий, послеоперационная летальность достигает $68 \%[2]$.

Частота острой кишечной непроходимости составляет примерно 5 человек на 100 тыс. населения, а по отношению к экстренным хирургическим больным - до 5\%. Несмотря на современные технические и технологические достижения в абдоминальной хирургии и послеоперационной интенсивной терапии результаты лечения больных с острой кишечной непроходимостью неутешительны, так как летальность составляет 17-21\% [3.4].

Ущемление развивается у 8-20\% больных с наружными брюшными грыжами. Если учесть, что «грыженосители» составляют около 2\% населения, то общее количество больных с этой патологией достаточно велико в практике экстренной хирургии. Среди пациентов преобладают лица пожилого и преклонного возраста. Летальность у них достигает $10 \%$.

Важным аспектом в комплексной терапии тяжелых пациентов и профилактике послеоперационных осложнений является раннее энтеральное питание, а именно поэтапное его введение. Благодаря энтеральному питанию поддерживается трофический гомеостаз, проводится коррекция метаболических и структурных нарушений пациентов. Установлено, что у тяжелобольных пациентов белковый и энергетический дефицит часто приводит к тяжелой полиорганной недостаточности. Установлена прямая связь между трофической недостаточностью пациентов и их летальностью[5,6]. Острые нарушения циркуляции, клеточная гипоксия и дистрофия являются последствиями операционно-хирургического стресса. Эти события в дальнейшем переходят в синдром стрессового метаболизма- гиперкатаболизма. Этот синдром характеризуется повышенным распадом белков, избыточ- ным образованием свободных жирных кислот, кетоновых тел и т.д. В результате данных событий снижается эффективность лечебных мероприятий, а в дальнейшем, если не предпринять меры по коррекции данных нарушений, развивается тяжелый патологический процесс, который может перерасти в полиорганную недостаточность. В критическом состоянии при определенных причинах (возраст, постельный режим, иммобилизация) организм начинает терять мышечную массу $[7,8]$. Энергетические потребности пациентов в обычных условиях составляют не более 25-30 ккал/ кг, а потери азота 10-11 г в сутки. В то же время при некоторых радикальных операциях на органах пищеварения энергетические траты могут достигать 35-45 ккал/кг, а потери азота 20-30 г в сутки. Данный показатель в 2-3 раза превышает среднесуточные потери азота у здорового человека. Во время стресс- голодания организм больных за дефицит 1 г. азота $(6,25$ г. белка) расплачивается 25 г. собственной мышечной массы. Энтеральное питание является приоритетным методом в выборе искусственного лечебного питания, так как в последние 15 лет стала преобладать позиция «если ЖКТ работает используй его, а если нет, то заставь его работать». При длительном отсутствии пищевого химуса в кишке происходит дистрофия и атрофия слизистой оболочки, снижаются моторная и ферментативная активность, нарушается выработка кишечной слизи и секреторного иммуноглобулина А. Также возникает контаминация условно-патогенной микрофлоры из дистальных и проксимальных отделов кишечника. При разрушении барьерной функции кишечника, транслокации микробов и токсинов в кровь возникает избыточная продукция провоспалительных цитокинов, в результате это приводит к системной воспалительной реакции и истощению моноцитарно-макрофагальной системы. Данные последствия повышают риск септических осложнений. При обеспечении структурной целостности и сохранение функциональной деятельности пищеварительной системы значительно улучшаю результаты лечения. Энтеральное питание является важным аспектом в профилактике острой кишечной недостаточности. Основными принципами энтеральной поддержки является раннее начало, определенная последовательность и мониторинг ее эффективности.[9]

То есть, ранее начало сбалансированный состав энтерального питания увеличивает выживаемость пациентов в послеоперационном периоде, уменьшает смертность, уменьшает количество койко- дней пациентов в стационаре.

В настоящее время имеются единичные работы о оценке эффективности раннего энтерального питания при резекции тонкой кишки .[12] 
Таблица. 1. Распределение по возрасту и полу в основной группе.

\begin{tabular}{|c|c|c|c|c|}
\hline \multirow{2}{*}{ Пол } & \multicolumn{4}{|c|}{ Возраст } \\
\hline & $18-44$ & $45-59$ & $60-74$ & $75-90$ \\
\hline Мужской & 2 & 3 & 10 & 3 \\
\hline Женский & 1 & 2 & 8 & 1 \\
\hline Всего & 3 & 5 & 18 & 4 \\
\hline
\end{tabular}

Распределение по возрасту и полу в контрольной группе. Таблица. 2.

\begin{tabular}{|c|c|c|c|c|}
\hline \multirow{2}{*}{ Пол } & \multicolumn{4}{|c|}{ Возраст } \\
\hline & $18-44$ & $45-59$ & $60-74$ & $75-90$ \\
\hline Мужской & 2 & 4 & 10 & 2 \\
\hline Женский & 2 & 2 & 7 & 1 \\
\hline Всего & 4 & 6 & 17 & 3 \\
\hline
\end{tabular}

\section{распределение больных по причине некроза (нозологии)}

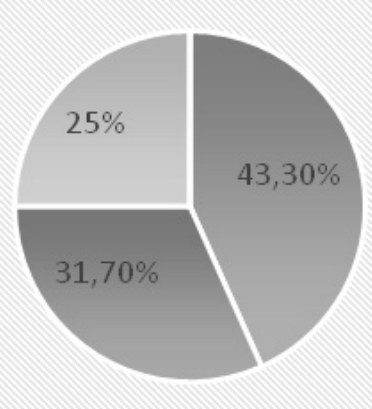

- острое нарушение мезентериального кровообращения

- острая странгуляционная непроходимость

пщемленная урыжа

Рис. 1

\section{Цель работы}

Улучшение результатов лечения больных с экстренной хирургической патологией тонкой кишки путем оптимизации программы нутритивной поддержки.

\section{Материал и методы}

Исследование является проспективным, проводилось на базе БУ «Сургутская окружная клиническая больница» у пациентов, госпитализированных по экстренным показаниям в хирургический стационар.

В исследовании включено 60 пациентов.

Критерии включения: возраст старше 18 лет, экстренный характер операции, объем операции - резек- ция тонкой кишки с формированием анастомоза, оперированных в экстренном порядке на тонкой кишке.

Критерии не включения: гематологические заболевания, терминальная почечная и печеночная недостаточность, сахарный диабет 1 и 2 типа; наличие распространенного перитонита в фазе сепсиса, тяжелая сопутствующая патология в стадии декомпенсации, субтотальные резекции тонкой кишки.

Больные были разделены на 2 группы в зависимости от типа нутритивной поддержки: группа А и группа Б: основная группа (n-30) - энтеральное питание, контрольная группа (n-30) - парентеральное питание.

Группы были сопоставимы по возрасту, полу, трофологическому статусу, объему резекции тонкой кишки, 
виду анастомозов, времени от поступления в стационар до оперативного лечения.

Всем пациентам при поступлении в стационар проводился комплекс диагностических обследований для установления диагноза в соответствии с национальными клиническими рекомендациями, проводился ряд дополнительных инструментальных методов исследования: ультразвуковое исследование органов брюшной полости - 14 пациентам (23,3\%), рентгенография органов брюшной полости - 36 пациентов (60\%), компьютерная томография органов брюшной полости 10 пациентов $(16,7 \%)$

Причины вызвавшие некроз тонкой кишки были следующие: острое нарушение мезентериального кровообращения в стадии некроза -26 пациентов (43,3\%), острая тонкокишечная непроходимость (странгуляционная) - 19 пациентов (31,7\%), ущемленная грыжа 15 пациентов (25\%).

По возрасту пациенты были распределены на 4 группы согласно классификации ВОЗ (2020 г.): 18-44 лет, 4559 лет, 60-74 лет и 75-90 лет.

В возрасте 18-44 лет - 7 пациентов (\%), 45-59 лет - 11 пациентов (\%), 60-74 лет - 35 пациентов (\%), 75-90 лет - 7 пациентов (\%). Медиана возраста (диапазон) основная группа: 33-80 лет; контрольная 63,5 (35-80 лет), $\mathrm{p}=0,322$.

По времени от поступления до проведения оперативного лечения (часы) в основной группе 2,4 \pm 1,87; в контрольной группе $-2,4 \pm 1,74, \mathrm{p}=0,693$.

По объему резекции пациенты распределены на 2 группы: сегментарная до 1 метра и обширная с длиной остающегося сегмента более 1 м.

Всем пациентам в предоперационном периоде с целью антиотикопрофилактики вводился антибактериальный препарат амоксициллин/клавулановая кислота 1,5 грамма внутривенно струйно за 30 минут до разреза, проводилась профилактика ВТЭО согласно клиническим рекомендациям.

После резекции пораженного сегмента тонкой кишки у всех больных сформирован однорядный ручной анастомоз Викрил + 3/0 с укреплением пластиной «ТАХОКОМБ». Завершалось оперативное лечение установкой назоинтестинального зонда, проведенного дистальнее связки Трейца на 30-40 см, что позволяет проводить активную раннюю гидратацию больных с первых часов, даже при нарушенной моторно-эвакуаторной функции желудка.
В послеоперационном периоде пациенты обоих групп получали интенсивную терапию в отделении реанимации и интенсивной терапии., которая включала в себя: инфузионную, профилактика стресс-язв, венозных тромбоэмболических осложнений. Всем пациентам проводилась мультимодальная анельгезия.

Пациентам основной группы (30 больных), в первые сутки послеоперационного периода вводился мономерно-солевой энтеральный раствор 500 мл капельно через назогастральный или назоинтестинальный зонд. Скорость введения 3 мл в минуту. Каждые 3 часа проводился обязательный контроль остатка путем активной или пассивной аспирации кишечного содержимого.

Со вторых суток, пациентам которым не планировалось проведение этапных релапоратомий дополнительно вводилась специализированная энтеральная смесь «Интестамин», содержащая глутамин, антиоксиданты. Объем вводимой смеси 300-500 мл в сутки, скорость введения 20 мл/час. Обязательно в первые 3 соток вводись энтеросорбенты «Неосмектин», для активной энтесорбции и предупреждения транслокации микрофлоры. Доставка питательной смеси проводилась при помощи инфузомата «KANGAROO Pump».

Минимальное энтеральное питание полностью не восполняет необходимые белково-энергетические потребности организма, оно нацелено на обеспечение питания клеток слизистой оболочки тонкой кишки, улучшение внутрипросветной трофики ЖКТ и сохранение барьерной функции кишечника. Вместе с этим, правильно подобранное энтеральное питание способствуют снижению выраженности стрессорной реакции организма и гиперкатаболизма, более быстрому восстановлению функции кишки[5,6].

С третьих суток к введению интестамина, мономерно-солевого раствора вводили полимерную питательную смесь в объеме 300 мл в сутки, дозу постепенно увеличивали в нарастающем объеме доводя до 1000 мл в сутки. Диспепсических расстройств у пациентов не отмечалось.

По мере восстановления активной перестальтики, назоинтестинальный зонд удалялся - пациентам дробно вводили пероральное питание с помощью питательных смесей дробно (методом полного сипинга) на 1-2 дня в объеме 25-30 ккал/кг/сутки с постепенным сокращением перорального их потребления и введения соответствующего клинической ситуации лечебного рациона.

Пациенты контрольной группы (30 больных) сразу после оперативного лечения начинали введение пол- 
Таблица. 3. Динамика общего белка

\begin{tabular}{|l|l|l|l|l|l|} 
& $\begin{array}{l}\text { Исходное } \\
\text { значение }\end{array}$ & 1 сутки & 5 сутки & 7 сутки & 10 сутки \\
\hline Основная группа & $63,8 \pm 3,41$ & $58,7 \pm 3,33$ & $43,0 \pm 3,10$ & $45,4 \pm 2,91$ & $59,5 \pm 3,35$ \\
\hline Контрольная группа & $63,3 \pm 2,61$ & $59,1 \pm 1,92$ & $41,2 \pm 2,59$ & $41,1 \pm 2,71$ & $57,4 \pm 3,88$ \\
\hline $\begin{array}{l}\text { р- уровень } \\
\text { значимости }\end{array}$ & 0,886 & 0,927 & 0,026 & $<0,0001$ & 0,001 \\
\hline Различия достоверны? & нет & нет & да & да & да \\
\hline
\end{tabular}

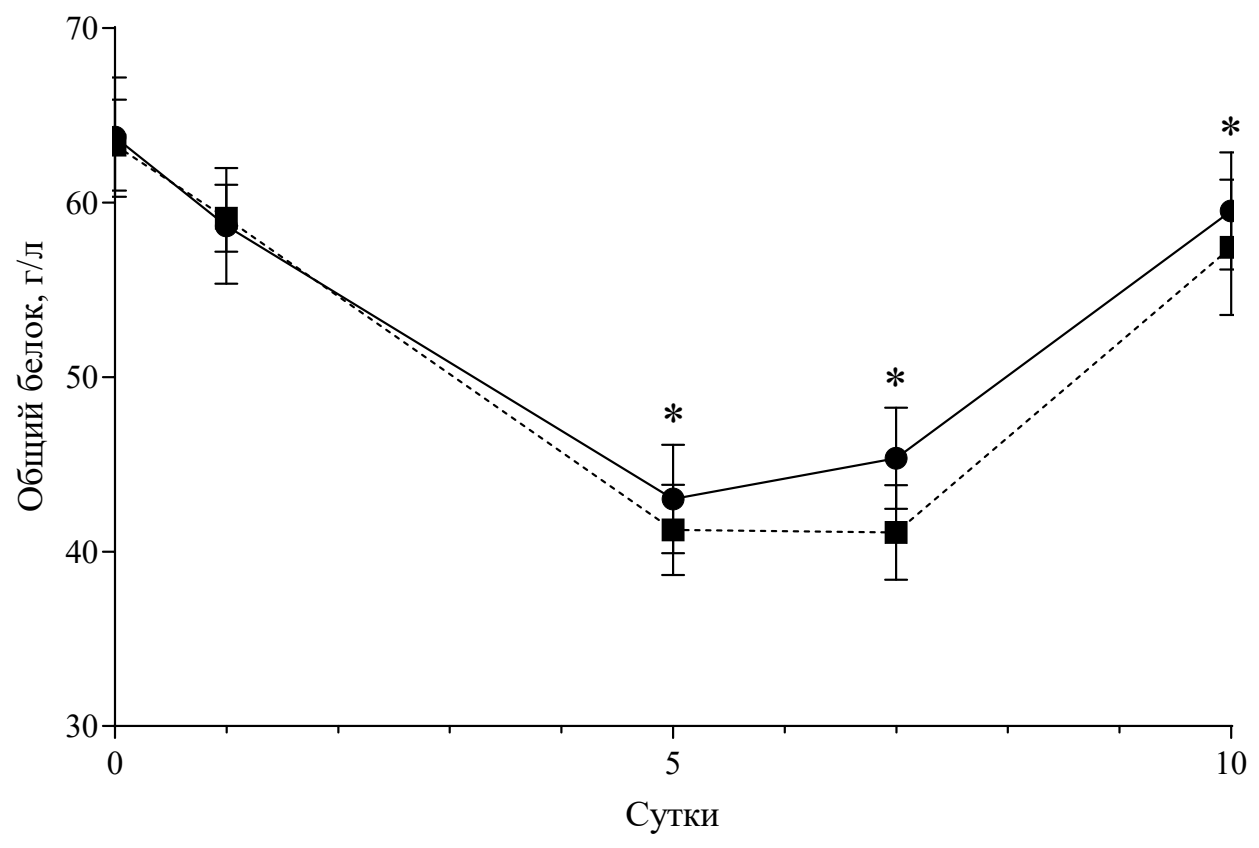

основная группа

контрольная группа

Pис. 2

ного парентерального питания. Препарат три в одном смоф кабивен перефирический. Дозирование парентерального питания проводили с помощью аппарата «Perfusor compact S». Для профилактики тромбоза венозного катетера катетр промывали 1 раз в сутки раствором гепарина 25-30 ЕД на килограмм массы тела в сутки.

Объем вводимого препарата определяли с учетом расчета белково-энергетической потребности каждого пациента.

По всем остальным параметрам терапии в послеоперационном периоде отличий не было.

Для определения базальной интенсивности обмена веществ использовалась формула Харриса-Бенедикта:

ОО (мужчины $)=66,5+(13,7 \times M T)+(5 x P)-(6,8 x B)$

ОО (женщины $)=655+(9,5 \times M T)+(1,8 x P)-(4,7 x B)$, где
МТ-масса тела, кг; Р-длина тела, см; В-возраст, годы

Далее в указанную выше формулу для определения ДРЕ последовательно вносились соответствующие коэффициенты метаболической поправки в зависимости от конкретной ситуации. (а именно фактор активности постельный режим 1,1; фактор повреждения 1,3).

Конечные точки сравнительного анализа данного исследования:

- Лабораторные - общий белок, альбумин, трансферрин;

- Функциональные - время восстановления функции ЖКТ (появление активных перестальтических шумов);

- Частота диспептических расстройств;

- Частота послеоперационных внутрибрюшных осложнений

- Послеоперационная летальность; 
Таблица.4. Динамика альбумина

\begin{tabular}{|l|l|l|l|l|l|} 
& $\begin{array}{l}\text { Исходное } \\
\text { значение }\end{array}$ & $\mathbf{1}$ сутки & $\mathbf{5}$ сутки & $\mathbf{7}$ сутки & $\mathbf{1 0}$ сутки \\
\hline Основная группа & $41,5 \pm 2,85$ & $36,1 \pm 1,88$ & $31,4 \pm 2,33$ & $32,8 \pm 2,04$ & $36,0 \pm 2,38$ \\
\hline Контрольная группа & $41,0 \pm 2,91$ & $33,8 \pm 1,57$ & $29,6 \pm 1,1$ & $29,1 \pm 1,18$ & $31,1 \pm 1,7$ \\
\hline $\begin{array}{l}\text { р-уровень } \\
\text { значимости }\end{array}$ & 0,537 & $<0,0001$ & 0,003 & $<0,0001$ & $<0,0001$ \\
\hline Различия достоверны? & нет & да & да & да & да \\
\hline
\end{tabular}

Таблица. 5. Динамика трансферрина

\begin{tabular}{|l|l|l|l|l|l|} 
& $\begin{array}{l}\text { Исходное } \\
\text { значение }\end{array}$ & $\mathbf{1}$ сутки & $\mathbf{5}$ сутки & $\mathbf{7}$ сутки & $\mathbf{1 0}$ сутки \\
\hline Основная группа & $2,4 \pm 0,23$ & $1,8 \pm 0,28$ & $1,5 \pm 0,19$ & $1,6 \pm 0,18$ & $2,2 \pm 0,29$ \\
\hline Контрольная группа & $2,5 \pm 0,16$ & $1,6 \pm 0,17$ & $1,4 \pm 0,16$ & $1,4 \pm 0,14$ & $1,7 \pm 0,14$ \\
\hline $\begin{array}{l}\text { р-уровень } \\
\text { значимости }\end{array}$ & 0,138 & 0,107 & 0,019 & 0,001 & $<0,0001$ \\
\hline Различия достоверны? & нет & нет & да & да & да \\
\hline
\end{tabular}

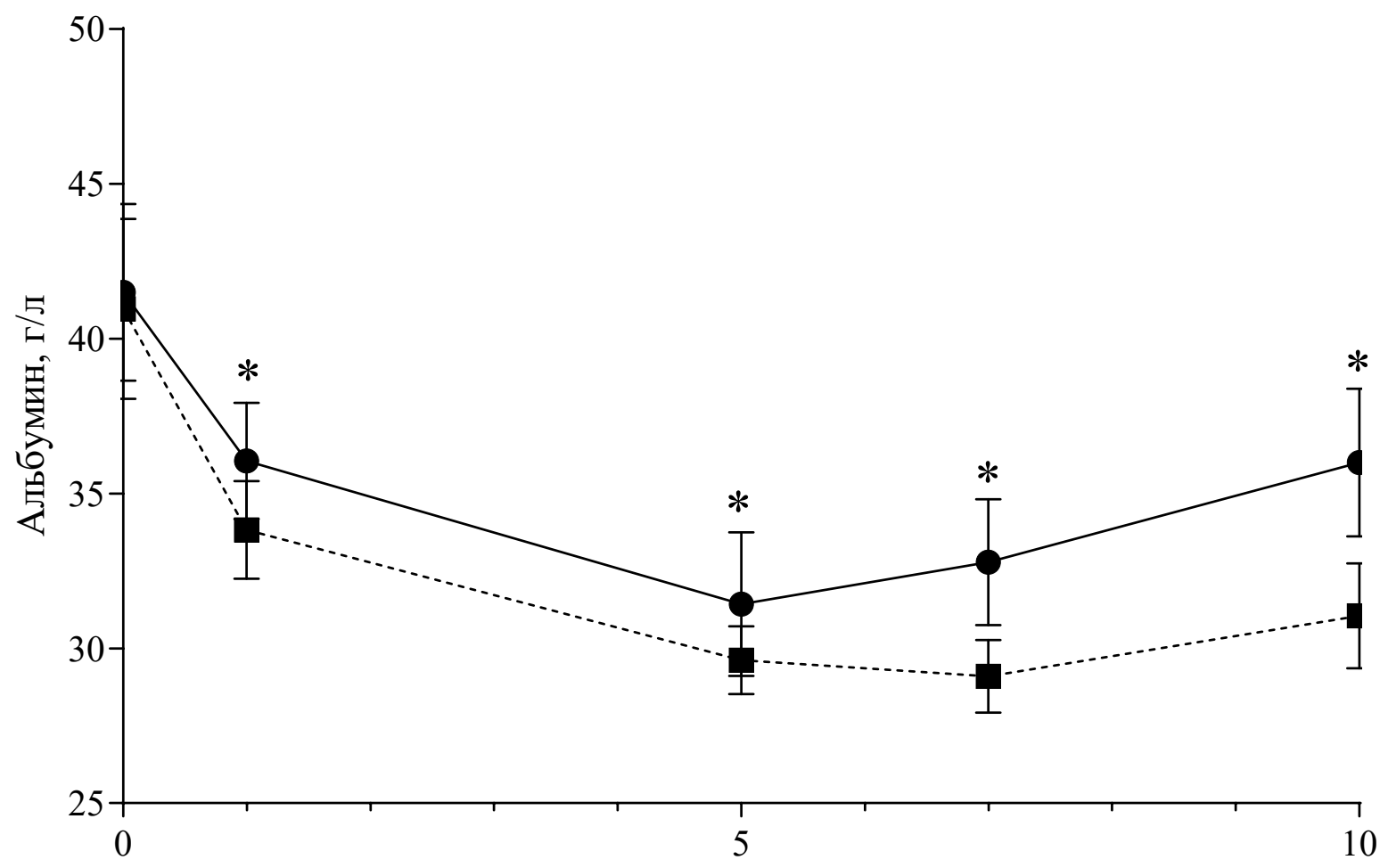

Сутки

основная группа

-. - контрольная группа

Рис. 3

- Длительность стационарного лечения.

Обработку полученных данных проводили с использованием программного обеспечения GraphPad Prism 8.0.1.
U-критерий Манна-Уитни использовали для сравнения непрерывных переменных (возраст, время до операции, показатели трофологического статуса, время до начала активной перистальтики). Точный критерий Фишера и критерий $X^{2}$ использовали для сравнения 
Таблица.6

\begin{tabular}{|l|l|l|l|}
\hline Осложнения & Основная группа & $\begin{array}{l}\text { Контрольная } \\
\text { группа }\end{array}$ & $\begin{array}{l}\text { р-уровень } \\
\text { значимости }\end{array}$ \\
\hline несостоятельность анастомоза & 5 & 12 & 0,153 \\
\hline абсцесс брюшной полости & 1 & 6 & 0,044 \\
\hline инфильтрат в брюшной полости в зоне анастомоза & 1 & 2 & \\
\hline острая ранняя кишечная непроходимость & - & 2 & \\
\hline ранняя спаечная кишечная непроходимость & 2 & 1 & \\
\hline эвентрация & - & 1 & \\
\hline
\end{tabular}

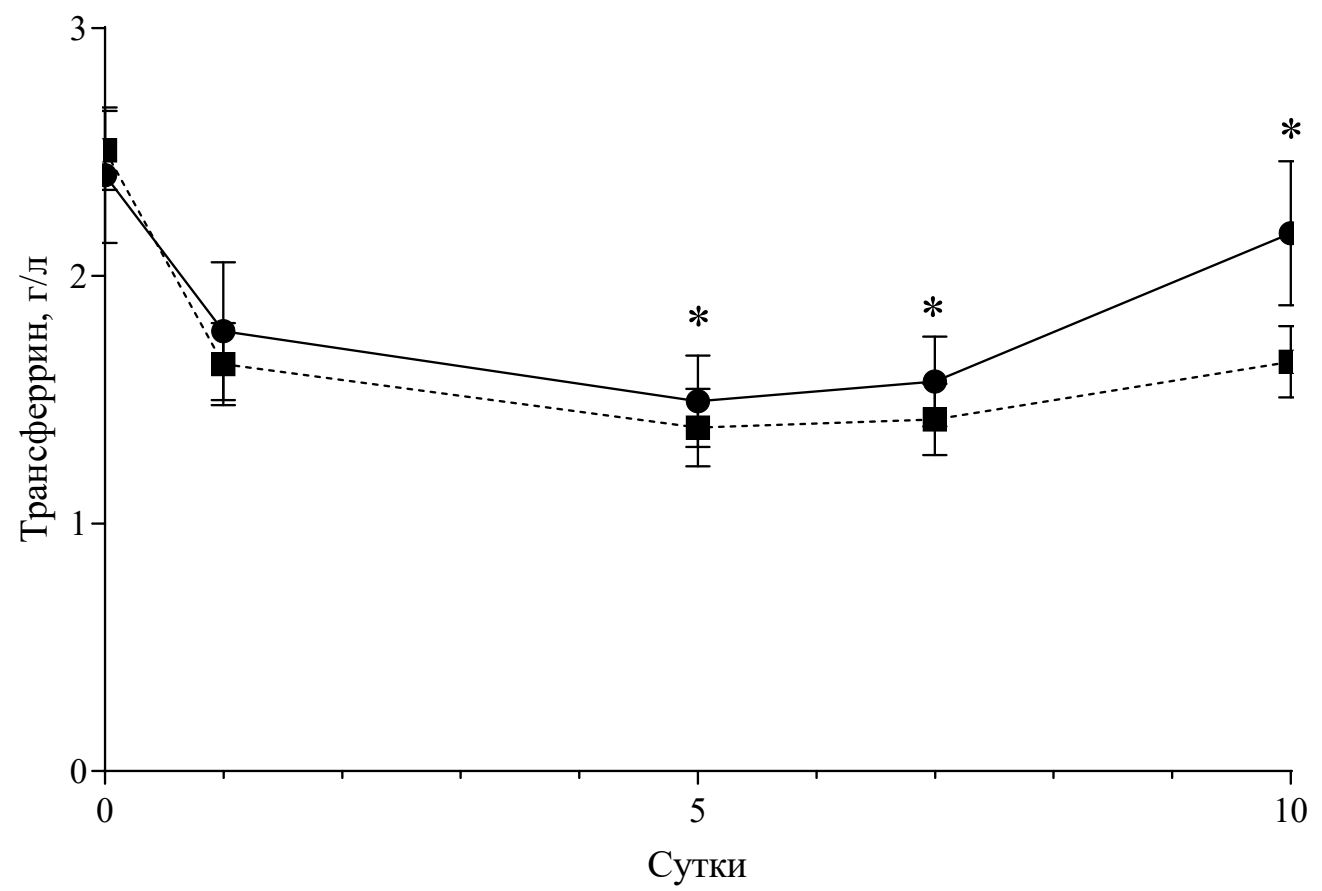

основная группа

контрольная группа

Рис. 4

дискретных переменных (пол, диагноз, сопутствующие заболевания, объем резекции, послеоперационные осложнения). Длительность пребывания в стационаре анализировали методами анализа выживаемости, так как данная статистическая модель позволяет наиболее точно оценить период пребывания элемента в совокупности до наступления терминального события (в данном случае выписки из стационара), а также использовать цензурированные данные. Значения р менее 0,05 считались значимыми.

\section{Результаты и обсужления}

Были проанализированы лабораторные показатели: уровень общего белка, альбумина и трансферрина в крови в динамике: перед оперативным вмешатель- ством, а также на первые, пятые, седьмые и десятые сутки после операции. В каждой временной точке данные основной и контрольной групп сравнивали с помощью U-критерия Манна-Уитни. Полученные данные представлены в таблицах 3,4,5 как среднее \pm стандартное отклонение. Показано отсутствие статистически значимых различий между группами по уровню общего белка, альбумина и трансферрина до операции. Однако в послеоперационный период наблюдается достоверно более быстрое восстановление всех исследованных лабораторных показателей в опытной группе по сравнению с контрольной.

На рисунках звездочкой $\left(^{*}\right)$ обозначены временные точки, в которых лабораторные показатели достоверно отличались между группами. 


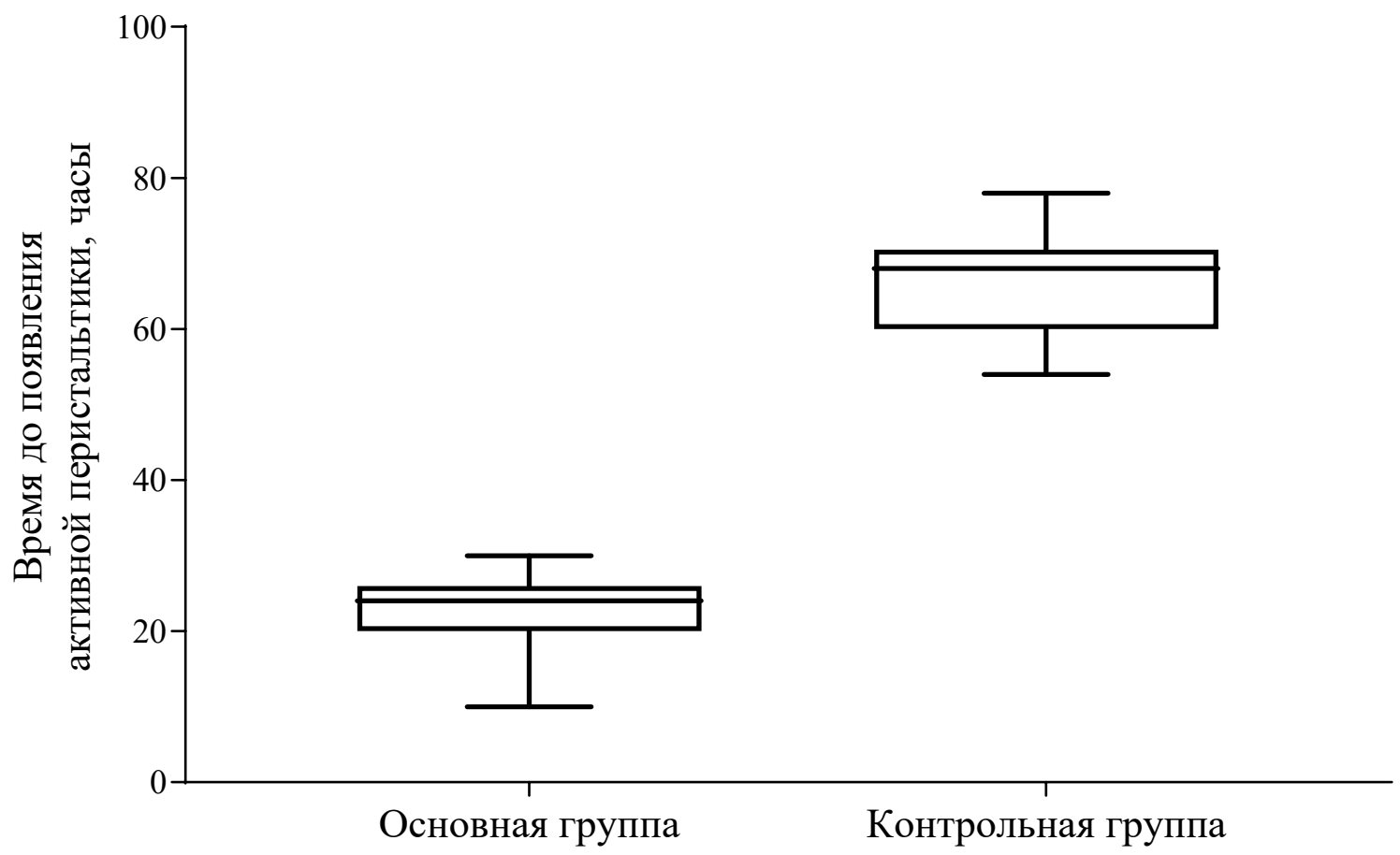

Рис. 5

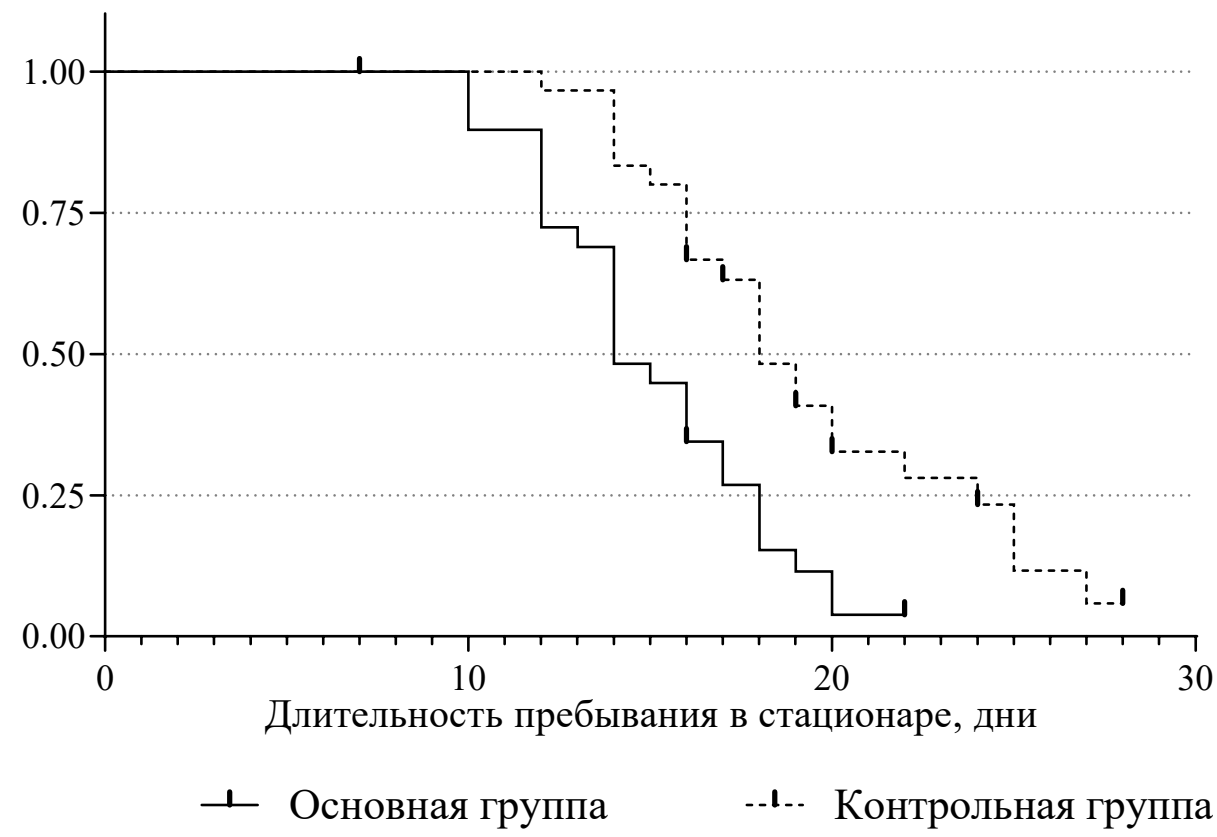

Рис. 6

Несмотря на то, что при оценке частоты послеоперационных осложнений между двумя группами (основная\%, контрольная\%) не было обнаружено статистически достоверных различий ( $p=0,319)$, в основной группе было выявлено меньшее количество случаев развития несостоятельности анастомоза по сравнению с контрольной группой. Эта разница была статистически значимой ( $p=0,044)$. Послеоперационные осложнения представлены в таблице 6.

Наиболее частыми причинами смерти явились несостоятельность анастомоза и абсцесс брюшной полости. 
Послеоперационная летальность в основной группе (3 пациента) была несколько ниже, чем в контрольной (6 пациентов). Однако данные различия не были статистически достоверны ( $p=0,278)$.

При анализе восстановления функционирования желудочно-кишечного тракта выявлено значительно более раннее появление активной перистальтики кишечника в основной группе $(22,9 \pm 4,47$ час.) по сравнению с контрольной $(66,1 \pm 6,81$ час.). Данные представлены как среднее \pm стандартное отклонение. Выявленные различия были статистически значимыми $(p<0,0001)$.

Выявлено статистически значимое сокращение длительности пребывания в стационаре в основной группе по сравнению с контрольной ( $p=0,0005)$. Медиана длительности пребывания в стационаре составила 14 дней в основной группе по сравнению с 18 днями в контрольной группе.

\section{Выво $\triangle \mathrm{b}$}

Разработанная поэтапная программа раннего энтерального питания у пациентов с резекцией тонкой кишки способствует более раннему восстановлению белково-энергетических потребностей, что позитивно влияет на более раннее восстановление функции желудочно-кишечного тракта, снижению частоты нарушений заживления анастомозов, сокращению длительности стационарного лечения и уменьшению послеоперационной летальности. Таким образом лабораторная и клиническая эффективность энтерального питания является основанием для его активного внедрения в клиническую пркактику у пациентов с резекцией тонкой кишки.

\section{ЛИТЕРАТУРА}

1. Баешко А.А, Климчук С.А, Юшкевич В.А. Причины и особенности поражений кишечника и его сосудов при остром нарушении брыжеечного кровообращения// Хирургия 2005 год. № 4.С. 57-60.

2. Климова Н.В., Ильканич А.Я, В.В. Дарвин. Компьютерная томография в диагностике острого нарушения мезентериального кровообращения //Радиология. Практика.2013. № 3.С.32-37.

3. Шестопалов А.Е., Лейдерман И.Н., Свиридов С.В. Метаболический ответ организма на стресс: Национальное руководство. Парентеральное и энтеральное питание. 2014. С. 142-60.

4. Макарова Е.Е. Роль ультразвукового исследования в диагностике острой тонкокишечной непроходимость: -Автореф.дис... канд.мед.наук. Российский государственный медицинский университет федерального агентства министерства здравоохранения и социального развития, Москва.,-2005. $25 \mathrm{c}$.

5. Петухов А.Б., Лященко Ю.Н. Питание больных с синдромом короткой кишки. В кн.: Лященко Ю.Н., Петухов А.Б. основы энтерального питания. М.: Вега-Интел; 2001: с. 195-237.

6. Парентеральное питание в интенсивной терапии и в хирургии. Методические рекомендации Минздравсоцразвития России, $2006 . c .44$.

7. Bruzoni M. Comparison of short bowel syndrome acquired early in life and during adolescence. Transplantation 2008; 86: 1: 63-65.

8. Hermanides J.et al. Glucose variability is associated with ICU mortality // Crit.care Med.-2010. — Vol.38 (3)

9. Waitzberg D.L., Torrinhas R.S. Fish oil Lipid emulsions and immune response what clinicians need to //NCP. - 2009.-Vol.24.-No.4

10. Луфт В.М. Энтеральное питание больных в неотложной медицине. Спб.: Фирма «стикс».2015 с. 16-27.

11. Ермолов А.С., попова Т.С., Пахомова Г.В., Утешев Н.С. Синдром кишечной недостаточности в неотложной абдоминальной хирургии (от теории к практике). М: МедЭксперт Пресс 2005. с. 460.

12. Краснов Е.А, В.В. Дарвин, А.Н. Варганова, Е.В. Бубович, Н.В. Климова, В.Е. Видуто. Экспериментальное обоснование раннего энтерального питания при резекции тонкой кишки. Вестник СУРГУ Медицина № 4 с. 94-102.

(c) Варганова Александра Николаевна ( Alexvarg24@уandex.ru ), Краснов Евгений Анатольевич, Дарвин Владимир Васильевич, , Аскерова Анастасия Александровна, Мамедов Султан Гаджи- Оглы. Журнал «Современная наука: актуальные проблемы теории и практики» 